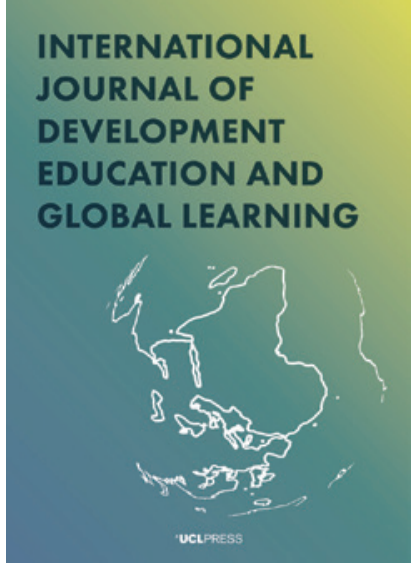

${ }^{ \pm}$UCLPRESS

\section{INTERNATIONAL JOURNAL OF DEVELOPMENT EDUCATION AND GLOBAL LEARNING}

e-ISSN: $1756-5278$

Journal homepage:

https://www.uclpress.co.uk/pages/international-journalof-development-education-and-global-learning

\title{
Global citizenship education discourses in a province in northern Italy
}

Sara Franch (i)

\section{How to cite this article}

Franch, S. (2020) 'Global citizenship education discourses in a province in northern Italy'. International Journal of Development Education and Global Learning, 12 (1): 21-36. https://doi.org/10.14324/IJDEGL.12.1.03

Submission date: 21 May 2019

Acceptance date: 16 January 2020

Publication date: 30 June 2020

\section{Peer review}

This article has been peer-reviewed through the journal's standard double-blind peer review, where both the reviewers and authors are anonymized during review.

\section{Copyright}

(C) 2020 Franch. This is an Open Access article distributed under the terms of the Creative Commons Attribution Licence (CC BY) 4.0 https://creativecommons.org/licenses/by/4.0/, which permits unrestricted use, distribution, and reproduction in any medium, provided the original author and source are credited.

\section{Open access}

International Journal of Development Education and Global Learning is a peer-reviewed openaccess journal. 


\title{
Global citizenship education discourses in a province in northern Italy
}

\author{
Sara Franch* - Free University of Bolzano-Bozen, Italy
}

\begin{abstract}
While global citizenship education (GCE) is becoming increasingly popular, it is also a complex and ambiguous concept that assumes different meanings. This article explores the dominant discourses that construct GCE in terms of the qualification, socialization and subjectification functions of education. Based on a qualitative study that used constructivist and informed grounded theory, the article focuses on the emergence of GCE in the educational discourse of the Province of Trento in northern Italy. The article shows elements of convergence and divergence between the perspectives of policymakers and teachers, and illustrates how in the discourses the three purposes of GCE - qualification, socialization and subjectification - are deeply intertwined and overlapping.
\end{abstract}

Keywords: global citizenship education, global education, citizenship education, intercultural education, grounded theory

\section{Introduction}

In the past decade, global citizenship education (GCE) has 'taken on the status of a "global" or "travelling" educational policy' (Oxley and Morris, 2013: 301-2). Mannion et al. (2011: 443) talk about a 'curricular global turn' characterizing the educational policies of many countries. GCE is increasingly popular, but it is also a complex and ambiguous concept that assumes different meanings. This article addresses the different interpretations of GCE, focusing on the perspectives of policymakers and teachers in the Province of Trento in northern Italy. Drawing on empirical research, the article analyses these different perspectives on GCE using Biesta's (2009) categorization of the purposes of education: qualification, socialization and subjectification. It shows elements of convergence and divergence between the perspectives of the different local actors and illustrates how in the discourses the three purposes of GCE are deeply intertwined and overlapping. The article ends by stressing that, while synergies are possible and can provide a comprehensive approach to GCE, policymakers and teachers should also be cognizant of the potential for conflict between the three dimensions, particularly between qualification and socialization, on the one hand, and subjectification, on the other.

\section{Global citizenship education: Diverse purposes and pedagogical frameworks}

GCE is a complex and ambiguous concept that 'emerges from a nexus of interrelated discursive fields, each of them contested as well as marked by particular histories, challenges, and possibilities' (Pashby, 2016: 69). The words 'global', 'citizenship' 
and 'education' represent narratives that, although apparently neutral, natural and unquestionable, are, in reality, contested discursive fields; therefore, when understood discursively, GCE 'becomes a complicated idea that is infused with various meanings' (Pashby, 2016: 71). It operates as a 'nodal point in policy discourse - a floating signifier that different discourses attempt to cover with meaning' (Mannion et al., 2011: 443).

Dill (2013) underlines that, in certain discourses, GCE is about fostering global competences, i.e. the knowledge and skills necessary to achieve prosperity in the highly competitive global marketplace; in others, it is about nurturing a cosmopolitan global consciousness, i.e. a vision of oneself as part of a global community of humanity, as a moral conscience to act for the good of the world and with an awareness of other perspectives. Bourn (2015) understands GCE as a pedagogy for global social justice, grounded in a global outlook, a recognition of power and inequality in the world, a belief in social justice and equity, and a commitment to reflection, dialogue and transformation.

As the ideas behind theoretical conceptualizations, policy initiatives or educational programming are never a neutral endeavour, the discourses of GCE are being engaged in ways that establish particular meaning and practices (Shultz et al., 2011). Drawing from Biesta's (2009) work, Sant et al. (2018) relate GCE to three purposes of education: qualification, socialization and subjectification. These should not be seen as entirely separate. On the contrary, in both policy and practice, they are often deeply intertwined and overlapping (Biesta, 2009).

\section{GCE as qualification}

In an approach privileging qualification, the purpose of education is to facilitate the acquisition of a certain set of knowledge, skills and dispositions to do something and to function in society (Biesta, 2009). In terms of GCE, knowledge and skills pertain to the acquisition of global and intercultural competences (Sant et al., 2018). GCE as qualification is related to economic global citizenship (Oxley and Morris, 2013) and a discourse that responds to the technical-economic instrumentalist agenda of GCE identified by Marshall (2011). In this discourse the purpose of GCE is to create economically competitive citizens who are advantaged because of their particular knowledge, skills and attitudes. Equally important is building a pool of human resources with the competences that a country needs to position itself in the global market and achieve a competitive and dynamic knowledge-based economy (Sant et al., 2018). The dominant perspective is not about fostering a global citizen committed to social justice, but rather a global entrepreneur (Franch, 2019). Within this discourse, educational institutions emphasize that in an increasingly interconnected and competitive global market, a knowledge of the world, foreign languages and skills such as adaptability and cross-cultural sensitivity are highly beneficial to students, as they 'foster a kind of borderfree mobility seen to enhance individual (economic) success in the world' (Jorgenson and Shultz, 2012: 3). An apt example of GCE as qualification is the new Organisation for Economic Co-operation and Development (OECD) PISA 2018 Global Competence Framework (Franch, 2019). It provides a definition of global competences on the basis of a prescriptive set of knowledge, skills, attitudes and values, and proposes a set of tools and criteria to assess and certify adolescents' global competences (OECD, 2018).

\section{GCE as socialization}

In an approach privileging socialization, the purpose of education is to impart certain norms and values to students so that they can become members of particular cultural, 
social and political orders (Biesta, 2009). In terms of GCE, these norms and values relate to becoming good citizens of the world. The main emphasis is on fostering citizens who are committed to a world culture based on human rights, pacifist values, cohesiveness and sustainability (Sant et al., 2018). GCE as socialization has points in common with the global consciousness interpretation identified by Dill (2013). It is related to moral and cultural global citizenship and the mainstream perspective that characterizes environmental global citizenship (Oxley and Morris, 2013). A socialization approach focuses on universal human values; however, this, according to Bamber et al. (2018: 207), is problematic because it fails to 'recognise the liquidity, historicity and evolution of difference'. The OECD PISA Global Competence Framework includes this perspective and therefore merges GCE as qualification with GCE as socialization, but a more fitting example of GCE as socialization is UNESCO's (2015) GCE pedagogical framework (Franch, 2019). Here, the good global citizen is defined in relation to three domains of learning (cognitive, socio-emotional and behavioural), but the socioemotional one is the most relevant and focuses on promoting a sense of belonging to a common humanity and the sharing of values and responsibilities based on human rights. The framework recognizes the unfairness and unsustainability of the current global system, but the approach is essentially about a better distribution of resources to alleviate poverty, rather than a fundamental questioning of the system or political action to achieve social justice (Franch, 2019).

\section{GCE as subjectification}

In an approach that privileges subjectification, the purpose of education is to facilitate independence from 'existing orders' and support 'those educated to become more autonomous and independent in their thinking and acting' (Biesta, 2009: 8). In terms of GCE, this means promoting 'a global citizenship from below' and a space for 'counterpractice', i.e. 'education on non-dominant knowledges and values' (Sant et al., 2018: 25-6). GCE as subjectification is associated with social and critical global citizenship (Oxley and Morris, 2013) and an ecocentric version of environmental global citizenship (Burdon, 2012; Mylius, 2013). De Oliviera Andreotti's (2015: 221) 'global citizenship education otherwise' is an apt example of GCE as subjectification. Andreotti (2010: 245) underlines that the post-traditions, in particular poststructuralism and postcolonialism, have the potential to provide educators with conceptual tools that will help them 'pluralize epistemologies and possibilities for thinking and practice'. Her GCE approach does not provide learners with normative ideals of democracy, freedom, rights and justice that are presented as universal, but rather is meant to facilitate ethical, responsible and responsive ways of seeing, knowing and relating to others 'in context'. It stimulates learners 'to imagine otherwise' (de Oliveira Andreotti, 2015: 221). Her approach is an alternative to mainstream GCE as qualification and socialization that is dominant in educational theory and practice. However, this critical GCE may not move beyond experimentation by individual educators and teachers as, according to Marshall (2011), a more systematic transition into curricula may currently be unrealistic and unworkable.

\section{Methodology: Constructivist and informed grounded theory}

Considering the diverse discourses constructing different meanings of GCE, this article explores how GCE is conceptualized in the Province of Trento in northern Italy. In 2015, this province adopted the concept of GCE and initiated policy changes to integrate it within the curricula. The article draws on the findings of qualitative research that was undertaken 
to study the processes through which GCE was constructed by local policymakers and teachers. It used grounded theory (Glaser and Strauss, 1967; Corbin and Strauss, 2008), in particular the constructivist interpretation promoted by Charmaz (2014) and the informed version suggested by Thornberg (2012). As GCE emerged as a new educational discourse in this province, grounded theory (GT) enabled learning about the participants' meanings without imposing a pre-existing GCE pedagogical framework.

The main data-gathering method was intensive interviews with provincial decision-makers, key informants and teachers. A flexible attitude characterized the data-gathering process as 'in the midst of the research, questions may arise that impel researchers to construct new data-gathering methods and to revise earlier ones' (Charmaz, 2014: 28). Intensive interviewing was hence complemented by a thematic analysis of relevant provincial policy documents on international development cooperation and education.

Intensive interviews were conducted in 2017 with five provincial decision-makers and key informants representing the International Development Cooperation Office, the provincial Education Office, and two centres involved in providing research and training on education and international development. Four of the five interviewees were members of a provincial Expert Group on GCE, which included representatives of the province, civil society and schools. An additional decision-maker provided a written response to the interview questions. In the same period, 21 teachers from nine lower secondary schools (where the age of the pupils ranges from 11 to 14) were interviewed. The schools were located in both the main urban centres and rural valleys, had both a low and a high percentage of students with migrant backgrounds and were both included and not included in a provincial project aimed at integrating GCE into the curriculum.

\section{Table 1: Sample of schools included in the research}

\begin{tabular}{cllcl}
\hline & School & Location of school & Foreign students (\%)* & Project \\
\hline 1 & IC A & Town in rural valley & 10 & Included \\
2 & IC B & Town in rural valley & 15 & Included \\
3 & IC C & Town in rural valley & 8 & Included \\
4 & IC D & Town in rural valley & 18 & Not included \\
5 & IC E & Second main urban centre & 12 & Included \\
6 & IC F & Town in rural valley & 4 & Not included \\
7 & IC G & Suburb of main urban centre & 4 & Not included \\
8 & IC H & Main urban centre & 19 & Not included \\
9 & IC I & Main urban centre & 15 & Not included \\
\hline *Data of percentage of foreign students provided by the provincial Education Office.
\end{tabular}

The teachers were identified through personal contact, recommendation by the provincial Education Office and snowball sampling. All the teachers interviewed had some exposure to GCE through in-service education or their interest in GCE was known within and beyond their school. The majority of the teachers interviewed were female ( 85 per cent), taught humanities (62 per cent) and had between 11 and 20 years' teaching experience (47 per cent).

During the interviews, a flexible guide shaped an open and in-depth conversation. Particular attention was paid to deconstructing the idea of the researcher as an expert working with established theoretical and pedagogical frameworks. This made uncertainty and openness possible. The teachers shared their ideas and experiences, and were forthcoming about doubts and difficulties. 
The interview became 'a space, time - and human connection' (Charmaz, 2014: 80) for reflection and clarification.

All the interviews were recorded and then transcribed verbatim. Following GT, initial line-by-line coding was used to open up the data and explore fragments of text to reveal all the possible meanings that the text could generate (Tarozzi, 2008), generating more than 300 codes. Focused coding was then used to identify and develop the most salient codes, which were then put to the test with large batches of data. It advanced the theoretical direction of the research.

Iterative strategies between data collection and analysis were used to continually focus the data collection on the ideas that were emerging from the analysis. Once tentative categories were constructed, theoretical sampling was used to seek pertinent data to 'elaborate and refine the categories' (Charmaz, 2014: 193). It meant going back into the empirical world to collect additional data through three methods: (1) 'theoretical thematic analysis' (Braun and Clarke, 2006: 12) of the provincial curricular guidelines, in particular the areas of history with citizenship education and geography; (2) intensive interviews with two additional key informants from the provincial Education Office; and (3) a meeting with the teachers already interviewed (nine teachers from four schools).

The conceptual categories constructed from the empirical data were combined and placed in dialogue with theoretical concepts, in particular the types of global citizenship outlined by Oxley and Morris (2013), and the categorization of the purposes of education developed by Biesta (2009) and applied to GCE by Sant et al. (2018). A certain level of resonance was found, which led to the use of these theoretical concepts to enhance the abstraction of the empirical categories and construct a coherent 'analytic story' (Charmaz, 2014: 150). Hence, in line with constructivist and informed GT, the findings of the study are 'thoroughly grounded in data by GT methods while being informed by existing research literature and theoretical frameworks' (Thornberg, 2012: 249).

\section{Institutional context: Dominant discourses in the provincial policies and perspectives}

The literature highlights that the institutional policy environment plays a crucial role in the integration of GCE in formal education. Tarozzi and Inguaggiato (2018) underline the important role of policymakers in promoting GCE through the issuing of policy documents that establish a normative framework for teachers' action and the provision of funding for activities in schools.

In the Province of Trento, the local government promoted the integration of GCE into the curriculum. The fact that the province enjoys special autonomous status within the Italian regional system was key as it allowed the local government to initiate changes more easily. A few timid modifications were introduced into the provincial education law to include a reference to global citizenship in the article listing the objectives of the schooling system. This was considered a key step that could lead to a subsequent modification of the curricular guidelines, which currently do not include a global citizenship perspective.

However, the province is not a monolithic entity that embraced GCE and cohesively pursued its integration within school practice. Rather, two key offices played different roles and, equally, displayed divergent priorities and agendas. The International Development Cooperation Office initiated the legislative change and managed a European project supporting the integration of GCE in schools. The 
provincial Education Office took a backseat role in the project and, more generally, in the promotion of GCE. The European project provided an opportunity to mobilize a local constituency of representatives of the province, civil society and schools that supported GCE. But it also revealed the tensions within the administration between its different visions and policy priorities as well as the difficulties in developing coordinated and coherent actions on GCE:

The difficulty I believe is primarily lived within the administration, in the sense that it discovers itself internally multiple and therefore not as a monolithic block that decided a direction and is following it, but rather as being made up of one hundred heads that pull in different directions. So, the fact that the province is actually on board means that one Office is on board, a portion of this mammoth being is on board, and it makes an extreme and enormous effort to dialogue with other offices ... So, this is probably, the biggest challenge to manage. (Member of expert group 2)

The different positions and priorities that emerged were clearly in relation to how the concept of GCE was viewed and used by the different provincial offices.

\section{GCE in the provincial international development discourse}

The International Development Cooperation Office identifies GCE as one of the key pillars of its policy. GCE is seen as a new framing paradigm of international development. It facilitates an understanding of international relations in terms of rights and relationships between citizens, rather than aid relations based on need. In this discourse, GCE is located within a vision of development that merges economic growth with a rights-based perspective, which is broadly in line with the UN's 2030 Agenda and the Sustainable Development Goals.

The international development discourse emphasizes the interdependence that characterizes the globalized world and the interconnectedness of people. GCE is framed within a perspective that recognizes the unfairness and unsustainability of the current global system, but the approach is essentially about making the system more humane and sustainable, rather than fundamentally questioning and transforming it. Within this perspective, GCE is an educational priority, necessary to foster a global consciousness, particularly in children and young people:

the global challenges (poverty, inequality, forced migrations, climate change, conflicts), that international development cooperation aims to contribute to tackle and resolve, have their root causes in the mechanisms of the global economy and in the dominant development model ... The Province of Trento wants to responsibly play a role ... Particularly it wants to engage in GCE, especially in schools, in order to equip young people with the tools to know, interpret and consciously act in an increasingly interdependent world, where the choices of everyone have repercussions at the planetary level. (Provincial Guidelines for international cooperation, 2016: 2)

In this case, GCE is framed within a socialization approach that is focused on human rights and cosmopolitan values. It is about fostering a respectful global citizen who understands global dynamics and moves in our interconnected and interdependent world in the right way. In the dominant narrative, this global citizen is primarily a consumer adopting ethical and sustainable practices: 
if you think in this way [with a global citizenship perspective], you are a different consumer, you are concerned about the products you buy, you are a citizen who uses public transport, is aware of what is in one's smart phone ... of the use of natural resources and who knows that one's choices have an influence. And therefore GCE is about having competences that allow me to know and understand these issues, and that make me also act in a certain way. Therefore there is also a dimension of action ... in my daily life. (Provincial representative b)

While predominantly framed within a socialization approach, the discourse of the international development sector also includes critical perspectives related to a subjectification approach. There is an emphasis on the need to decolonize our thinking, to question our taken-for-granted conceptual and interpretative frames, to challenge what is considered natural, thus unveiling the conventional and constructed nature of reality. There was also an acknowledgement of the need to learn from visions, world views and approaches from the Global South:

We are having a lot of dialogue in Europe on these issues and on GCE. I think it would be very interesting to hear about other approaches in other parts of the world. It is already a lot that we managed to open up to the European level, but I think it is also a limit, to be overcome because it would be nice to incorporate other visions, other pedagogies, other thoughts. (Provincial representative b)

\section{GCE in the provincial education discourse}

GCE is not explicitly endorsed by the provincial Education Office and is therefore still a marginal issue in provincial education policies. Global citizenship is seen as an academic label that may have value in terms of explaining the complexity of today's globalized world, but is probably provisional and fickle, just as fashion is:

lastly, this concept of global citizenship was born, right? So, well, I am a bit against labels and think that these labels are really the paradigms that academia uses to frame particular historical phases, then they are generally overcome, changed. One looks for some labels ... Global citizenship is a multi-dimensional concept that tries to capture the complexity of today's living, of contemporaneity. But, these labels, everything can be summed up by them ... Well, I am not very attached to these labels. (Provincial representative c)

GCE is considered irrelevant for a school system that is centred on the qualification function of education, and particularly on three key priorities:

- the strengthening of young people's employability through a school system that facilitates knowledge of and links to the job market, and the involvement of the private sector in building students' knowledge and skills

- the improvement of students' linguistic competences, particularly in English, through the promotion of a trilingual school (Italian, English and German)

- the digitization of schools and strengthening of students' digital competences.

In the discourse, there is an emphasis on global competences, related to knowledge of foreign languages as well as entrepreneurial and digital skills. These are valued because they respond to the province's objectives of equipping students with the 
skills needed to succeed in the global economy, while at the same time enhancing the internationalization and economic development of the province:

Educate and train a population with adequate skills and knowledge, able to face the processes of innovation and internationalization, able to support the exercise of the rights/duties of active and responsible citizenship, as well as to reach and maintain an adequate level of economic development of the provincial territory. (Provincial Guidelines for the schooling system, 2015: 1)

The emphasis on global competences is reconciled with the socialization conception of citizenship education, where the main focus is not on global citizenship, but rather on a traditional idea of citizenship, interpreted as civil virtues. Citizenship does not have a global dimension, but is rather linked to fostering a sense of belonging to a clearly defined local and cultural identity:

this concept of citizenship has developed mainly in the sense of having an awareness of where you are, the community you belong to, the history you belong to ... We are Trentini; and Trentino has these characteristics because it has a history, because in this history a number of things happened, that have moulded characters, traditions and cultures. Therefore, [the] creation of a stronger bond, a greater awareness of one's own historical roots, and this is citizenship. (Provincial representative e)

In this perspective, the function of citizenship education is to foster the development of a respectful and responsible local citizen. Promoting respect for the rule of law and legality as well as stressing social cohesion in the context of culturally diverse local communities are the key areas in the province's citizenship education discourse.

\section{Diverging or converging perspectives?}

Divergent perspectives characterize the provincial government. The International Development Cooperation Office endorses and promotes a vision of GCE that is strongly aligned with UNESCO's GCE framework. Its agenda broadly reflects what Marshall (2011) calls a global social justice instrumentalism, where the aim of integrating GCE into the curriculum is to facilitate an understanding of the economic, political, legal, cultural and environmental dimensions of globalization, and the injustices created by the dominant development models, as well as promote ethical and sustainable attitudes and behaviours. The provincial Education Office, on the other hand, does not endorse GCE. It remains committed to a civics/citizenship education that has a strong emphasis on the rule of law/legality and social cohesion as well as a focus on local cultural identity. Its agenda reflects what Marshall (2011) calls a technical-economic instrumentalism, where the curriculum is related to the economic changes that characterize the world economy and what is required for the future employability of students. The perspectives and agendas of the two offices, while apparently diverging, do have some elements of convergence. Two discourses are dominant: (a) excellence and competitiveness; and (b) internationalization.

In the excellence and competitiveness discourse, being competitive does not mean being ruthless and crushing others, but rather pursuing excellence and possessing certain global and intercultural skills and attitudes that make you competitive in the global economy. Under this discourse, the perspectives of the two provincial offices converge: 
I think that GCE really challenges a particular model of competition, right? ... GCE tells you, yes, you are competitive because you can understand the dynamics in the rest of the world, you can move in the world as if it were your home, because you can understand, relate, and move in the international sphere ... therefore I believe it is a different competitiveness ... the Province, for example, promotes this trilingualism, language skills as an instrument for being competitive. We believe that promoting GCE can be absolutely integrated with this trilingual project. (Provincial representative b)

we are very competitive ... in our schools we are never ashamed of using the term competitiveness ... Competitiveness should not be about crushing others, competitiveness is to reach higher goals. It is not the competitiveness of profit, but the competitiveness of excellence. (Provincial representative c)

Internationalization is a very dominant discourse. In the provincial education policy, it is named as a key objective of the schooling system. The guidelines for international development talk about responsible internationalization, informed by the principles of international development and GCE, and therefore with a human face. The question that can be raised is whether the internationalization pursued by the provincial government will be coherent with the objectives of international development and GCE? Or, rather, is it going to be the other way around - will international development and GCE become instruments to further the economic internationalization of the province?

Another key question is how these different visions and priorities are picked up by schools and influence the way GCE is conceptualized by teachers. The next section investigates the extent to which the perceptions of teachers reflect or fail to reflect the provincial discourses.

\section{The marginality of GCE in the curriculum}

GCE has marginal status within the provincial education policies and the formal curriculum. Analysis of the curricular guidelines highlights that there are some references to concepts and topics related to GCE in the citizenship education curriculum, and in the subjects of geography and history. A global citizenship perspective is virtually absent from other subjects: the focus is on traditional subject-specific knowledge and skills. Overall, in the curricular guidelines, the concepts of global citizenship and GCE are not explicitly adopted and used to provide a global perspective to citizenship education and the other subjects.

In this context it is not surprising that, in the schools studied, GCE is a marginal presence. It is invisible and characterized by the personal and self-made efforts of a few motivated and committed teachers. GCE is not an educational imperative, but rather a sporadic occurrence. Three broad strategies are used by teachers in relation to GCE: (1) avoidance; (2) pioneering; and (3) building communities of peers (Franch, 2020).

\section{Avoidance}

Avoidance is used by those teachers who follow a traditional curriculum and do not engage with global citizenship perspectives and issues. They follow the curricular guidelines which, as previously stated, do not provide a global citizenship dimension to the curriculum. Although the curricular guidelines are competence-based, these 
teachers tend to follow a rigid syllabus of disciplinary topics, not prescribed by the guidelines, but rather grounded in tradition, i.e. what has always been taught in that subject.

\section{Pioneering}

Pioneering characterizes motivated and willing teachers who interpret and manoeuvre the curriculum to provide students with opportunities to explore the global dimension. They imaginatively use the freedom and autonomy of teaching granted by the Italian Constitution, and draw from the fact that the curricular guidelines are competencebased. So, although the guidelines lack a global citizenship breath, they also do not prevent teachers from including GCE in their practice. Strategies used to incorporate a global perspective are: (1) designing specific GCE projects; (2) making choices about the curriculum; and (3) responding to prompts arising in class (Franch, 2020).

\section{Building communities of peers}

Pioneering teachers tend to engage with GCE mainly in the isolated spaces of their classrooms and subjects. They attempt to work within formal school structures, encountering much resistance; however, their main way of involving colleagues is through building informal communities of peers. Working closely with like-minded colleagues provides teachers with emotional and professional support. However, these communities are informal and often dependent on the bonds of friendship. Designing specific projects that involve colleagues is a key modality to engaging in GCE and is also a way to build communities of peers (Franch, 2020).

\section{GCE in teachers' discourse: Reproducing, ignoring or challenging the provincial policies}

The teachers interviewed showed significant confusion and hesitancy around GCE. Many of them were not familiar with the concept and said that they hardly use this term in their classrooms. The terms they generally use are 'citizenship education' and 'intercultural education'. The teachers acknowledge that in today's global world, citizenship education needs to assume a global perspective. They feel comfortable with the term 'GCE' and believe it captures the importance of adjusting citizenship education to the realities of a global world:

Citizenship education, that is, to educate young people to be citizens, and, in a global world, it goes without saying that citizens means citizens of the world. We are not educating them to something that is not there, we need to overcome nationalisms, we are connected, interconnected ... we educate them to be in this globalized world. (Teacher 7, school A, humanities)

However, they generally find it difficult to define what GCE is and what it entails in terms of teaching practice. Similarly to the findings of the study by Rapoport (2015), the teachers interviewed interpreted GCE through familiar discourses and paradigms, namely the concepts of citizenship education and intercultural education.

They see GCE as a natural extension of citizenship education and do not fully acknowledge the tensions that exist between GCE and citizenship education. The latter is, in fact, a nation-state-centred concept and therefore potentially in conflict with a global citizenship perspective. Moreover, the teachers added the global dimension 
to an already overstretched conceptualization of citizenship education, which includes everything that teachers cannot neatly fit into a particular subject. It also includes what can be more aptly referred to as promoting discipline and good behaviour.

In the teachers' discourse, citizenship education has a socialization function. It is consistent with the provincial education discourse centred on promoting democracy, rights and legality, and the moral and social development of students. Teachers stressed fostering respect for the rules of civil behaviour, starting from the rules that should be obeyed in the classroom and, more broadly, the school. Citizenship education is essentially about fostering respectful and responsible students. The assumption is that if young people learn to be respectful, well-behaved and cooperative students in the school environment, they will develop into good citizens in society. This perspective permeates the provincial curricular guidelines for citizenship education and clearly informed the way teachers conceptualize citizenship education:

and then the main thing, citizenship is experienced daily, in the classroom, all the dynamics that take place in the classroom, more or less consciously, are part of a citizenship education journey. Relationship dynamics, mutual respect. Here it's a training ground for your whole life, for the workplace, for any context. (Teacher 3, school I, humanities)

The dominant discourse with the provincial education policies rejects the concept of global citizenship and embraces a vision of citizenship that is aimed at fostering a sense of belonging to a clearly defined local and cultural identity. This vision was resisted by the teachers interviewed. Their ideas and practices were predominantly located within a vision of citizenship rooted in a cosmopolitan perspective. The latter was articulated in terms of fostering a cosmopolitan identity in line with moral global citizenship (Oxley and Morris, 2013). Strong emphasis was given to universal human rights, a sense of belonging to a common humanity and the similarities between humans that transcend differences and impose moral obligations towards distant others. This socialization perspective was reconciled with the qualification imperative of preparing young people for work in the global economy. While some teachers openly criticized the provincial focus on trilingual schooling, overall they did not challenge the provincial policy of shaping the schooling system to prepare young people for the global economy while also supporting the economic development and internationalization of the province.

The conceptualization of GCE through the intercultural education lens is consistent with the provincial education policies on the integration of migrant students into schools and with the focus on promoting respect for cultural diversity, active tolerance and peaceful coexistence in the curricular guidelines for citizenship education. Teachers' work centres on cultural global citizenship (Oxley and Morris, 2013). Similarly to citizenship education, their perception is that school can be a training ground for life in today's multicultural society, as it provides a space for relating to the ethnically and culturally diverse:

Today's big citizenship issues ... interculture, understood as the encounter of cultures, mutual knowledge, and the possibility of giving spaces of expression to everybody ... a great resource is the class, that is, in the classroom there is a large multicultural presence. Our classes, because of their composition, help. This, in my opinion, is the winning card, to make people understand that there are eyes, there is a name and surname ... because the migrants, they have them as classmates, that is, she is the migrant, the migrant is not an evil entity. (Teacher 13, school D, humanities) 
Some of the teachers were aware of the complexity of working in multicultural classes and displayed a high level of reflexivity in relation to their own perceptions of students with a migrant background, or the attitudes of these students towards being identified as culturally diverse or foreign. The approach of many teachers, however, was quite uncritical, with intercultural education being more of an aspiration than a reality of their practice. Accepting and respecting the 'other' presupposes a deep engagement with the concept of identity; however, the teachers did not clearly outline a multiple, fluid, dynamic concept of identity. They also did not seem confident in helping students to critically reflect on their identities, nor to exploring their values in an open, transparent and critical manner.

The scholarly literature highlights that often GCE is characterized by the behavioural dimension, i.e. to provide opportunities for students to be active and do something about the global issues they are addressing in school. This is considered problematic because it reinforces notions of the Northern student being able and capable of making a difference, while the Southern poor person is portrayed as a passive victim to be assisted (Bryan and Bracken, 2011; Blackmore, 2014; Jefferess, 2008). It also detracts from learning about the complex causes of poverty and encourages 'simplistic thinking' and 'quick-fix solutions' (Blackmore, 2014: 158). The emphasis on encouraging students to be active and do something to 'help' or 'solve' global issues did not emerge as a prominent feature of the way the interviewed teachers conceptualize GCE. Their perspectives reveal a strong focus on the concept of personal responsibility, with importance placed on encouraging students to engage in ethical and sustainable behaviours at the individual level. Fundraising and charitable work did not feature prominently in teachers' accounts. The marginality of the action agenda in the schools studied is a welcome departure from the paternalistic, ethnocentric and solution-focused perspectives that characterize GCE in some contexts. It opens spaces for teachers and students to engage critically with issues without the anxiety associated with finding solutions to global issues or crafting opportunities for students to 'make a difference' in the lives of distant others. Indeed, elements of criticality emerged from teachers' narratives. A few teachers talked about creating spaces where single stories can be challenged and different perspectives can find expression. They stressed the importance of questioning the assumed objectivity and truth of our knowledge, and of discussing with students the fact that history is not objective but is told from different points of view:

in history we talk about invasioni barbariche [the Migration Period during the decline of the Roman Empire around the 4th to 6th centuries AD] and then we discover that the Germans do not call them invasions but call them Völkerwanderungen, so migrations of peoples, so there is an ideological aspect that we begin to perceive and so we understand how history is interpreted by each people according to the own perspective. (Teacher 15 , school D, humanities)

One teacher explicitly referred to the importance of cognitive decentralization to move beyond an ethnocentric vision of the world:

work on cognitive decentralization, to simply make it clear that the way we have studied the world, and history, is a Eurocentric view, even simply projecting planispheres, as they are depicted in other countries: this above, this below, the fact that you can't find Europe anymore because it is in a little corner because maybe at the centre there is /... this displaces them [pupils] ...You can also make them reflect on how the European, even 
historically, has always assessed with its own meter, without valuing what was there, what he was finding. (Teacher 13, school D, humanities)

These elements of criticality are not necessarily in opposition to a discourse that focuses on activism. Indeed, they can be reconciled with a perspective that supports students to become democratic subjects, as suggested by Biesta (2014). Educators, as Mannion et al. (2011) underline, can focus on the kind of global citizenship practices that are possible within schools and society more generally and what and how students might learn from them. Yet, in the schools studied, this is not the case. The collective social and political dimensions of being citizens did not feature prominently in the way GCE is conceptualized. While a few teachers acknowledged that it is an important aspect to develop, for most of them, being a political citizen was somehow postponed to the future. The students are not yet considered citizens and are rather seen as citizens-inthe-making. Being active democratic subjects in society is hence seen as something they will do when they get older.

\section{Conclusions}

The education policies of the Province of Trento shape a schooling system that is aimed at preparing young people for the global economy while also supporting the economic development and internationalization of the territory. An emphasis on global competences is reconciled with a socialization conception of citizenship education which aims to foster the respectful and responsible local citizen. The main focus is not global citizenship, but rather a traditional idea of citizenship, interpreted as civil virtues, and a sense of belonging to a clearly defined local and cultural identity. The provincial international development discourse emphasizes the interdependence that characterizes the globalized world and the interconnectedness of people. GCE is considered a new framing paradigm for international development and a priority for education. In line with a cosmopolitan perspective and a socialization approach, GCE is about fostering the respectful global citizen, one who understands this interdependence and moves in the world in a responsible and sustainable manner. While the qualification discourse is dominant in educational policies, through narratives that focus on excellence, competitiveness and internationalization, it also permeates international development policies.

The teachers conflate GCE with citizenship education and intercultural education. They bring a global perspective to citizenship education, thus challenging the marginality of GCE in education policies and in the curricula. Their perspective is rooted in moral cosmopolitanism and a socialization approach aimed at fostering the good global citizen. Their approach significantly amplifies the dimension of GCE related to preparing students for life in a multicultural society and their perceptions remain situated within the qualification purpose that permeates the provincial education policies. The teachers merge different agendas: the economic (preparing young people for the global economy), the moral (helping others) and the cultural (fostering tolerance). They do not question the assumed naturalness of the global economy, the moral imperative or the emphasis on tolerance, but, similarly to the experience in an English school, they remain deeply situated within these agendas, while simultaneously contributing to their maintenance (Blackmore, 2014).

Elements of criticality in line with a subjectification perspective emerged in the way GCE is conceptualized by some representatives of the international development sector and by a few teachers, who stressed the importance of decolonizing our thinking and questioning the assumed naturalness of certain conventions. However, 
overall, GCE is conceptualized by both policymakers and teachers as a 'new moral pedagogy' that mixes qualification and socialization. As a result, other dimensions are overlooked, in particular those related to a subjectification approach which uses GCE as an ethical and political framework for the critical deconstruction and transformation of global structures of power and domination. GCE in the Province of Trento falls short of being a pedagogy for global social justice. Only a few provincial informants and teachers consider GCE as a pedagogical framework to help learners acquire a critical understanding of globalization, power and inequality in the world and the ways in which they and their nations are implicated in local and global problems (Bourn, 2015). Generally, teachers do not use GCE to critically explore identities and discourses so that learners may develop a dialogical, complex and dynamic understanding of their identities as well as the capacity to understand and interact responsibly with others while being self-critical of their own perspectives and positions (Pashby, 2016).

The findings of this study confirm that it is very challenging for critical versions of GCE that pursue subjectification to move beyond experimentation by individual educators and teachers. According to Marshall (2011: 424), a more systematic translation of critical GCE approaches in curricula may currently be unrealistic and unworkable, given that schools are located in wider societies that are 'reproducing powerful corporate cosmopolitan ideals entrenched in a set of neo-liberal and knowledge-economy norms'. It is the opinion of the author that policymakers and teachers do not need to situate their policies and practice completely within a qualification, socialization or subjectification approach to GCE, but can rather merge the perspectives. Synergy is certainly possible and can provide a comprehensive approach to GCE. A qualification approach does not necessarily need to focus on the competences to succeed in the global economy, but can build the knowledge, skills and dispositions essential for critical global citizenship, i.e. knowledge and understanding of global systems, structures and issues as well as the skills required for civic literacy and critical inquiry. A socialization conception, with its focus on humanistic and cosmopolitan values, can bring to the fore our common humanity and values rooted in human rights. But GCE demands that teachers and educators also foreground a subjectification approach centred on a critical pedagogy for global social justice (Bourn, 2015). This will facilitate a socio-political analysis of the root causes of global poverty and inequality, and a commitment to social transformation. A political perspective grounded in social justice is in fact necessary if GCE is to take political agency seriously. Moreover, a subjectification conception of GCE is required to facilitate the critical deconstruction of the dominant discourses that shape our understanding and actions.

The author believes that while synergy is possible, policymakers and teachers should also be cognizant of the potential for conflict between the three dimensions, particularly between the qualification and socialization dimensions, on the one hand, and subjectification, on the other. A GCE policy and practice that blindly supports qualification and socialization without analysing the current global dynamic, questioning its tenets, deconstructing dominant narratives and exploring alternative visions, is problematic. It reproduces ethnocentric and paternalistic perspectives and depoliticizes citizenship practices, thereby undermining a GCE approach that pursues subjectification. By foregrounding political knowledge and critical thinking skills (qualification) and human rights (socialization), while also drawing from voices that have been silenced by colonial epistemic violence, GCE can become a space that helps learners to become more autonomous and independent in their thinking and acting (subjectification). GCE can thus open opportunities for thinking otherwise and 
imagining alternatives to the current modern/colonial global imaginary (de Oliveira Andreotti, 2015).

\section{Notes on the contributor}

Sara Franch is a postdoctoral researcher at the Free University of Bolzano-Bozen, Italy. Her PhD research focused on global citizenship education. She has worked for over 20 years in the international development sector, managing programmes in Liberia, Sudan, Burma, Cambodia and Timor Leste, and developing projects and training activities on international development and global citizenship.

\section{References}

Andreotti, V. (2010) 'Postcolonial and post-critical "global citizenship education"'. In Elliott, G., Fourali, C. and Issler, S. (eds) Education and Social Change: Connecting local and global perspectives. London: Continuum, 238-50.

Bamber, P., Lewin, D. and White, M. (2018) '(Dis-) Locating the transformative dimension of global citizenship education'. Journal of Curriculum Studies, 50 (2), 204-30.

Biesta, G. (2009) 'Good education in an age of measurement: On the need to reconnect with the question of purpose in education'. Educational Assessment, Evaluation and Accountability, 21 (1), 33-46.

Biesta, G. (2014) 'Learning in public places: Civic learning for the twenty-first century'. In Biesta, G., De Bie, M. and Wildemeersch, D. (eds) Civic Learning, Democratic Citizenship and the Public Sphere. Dordrecht: Springer, 1-11.

Blackmore, C. (2014) 'The Opportunities and Challenges for a Critical Global Citizenship Education in One English Secondary School'. PhD thesis, University of Bath.

Bourn, D. (2015) The Theory and Practice of Development Education: A pedagogy for global social justice. London: Routledge.

Braun, V. and Clarke, V. (2006) 'Using thematic analysis in psychology'. Qualitative Research in Psychology, 3 (2), 77-101.

Bryan, A. and Bracken, M. (2011) Learning to Read the World? Teaching and learning about global citizenship and international development in post-primary schools. Dublin: Irish Aid.

Burdon, P. (2012) 'A theory of earth jurisprudence'. Australian Journal of Legal Philosophy, $37,28-60$.

Charmaz, K. (2014) Constructing Grounded Theory. 2nd ed. London: SAGE Publications.

Corbin, J. and Strauss, A. (2008) Basics of Qualitative Research: Techniques and procedures for developing grounded theory. 3rd ed. Thousand Oaks, CA: SAGE Publications.

De Oliveira Andreotti, V. (2015) 'Global citizenship education otherwise: Pedagogical and theoretical insights'. In Abdi, A.A., Shultz, L. and Pillay, T. (eds) Decolonizing Global Citizenship Education. Rotterdam: Sense Publishers, 221-9.

Dill, J.S. (2013) The Longings and Limits of Global Citizenship Education: The moral pedagogy of schooling in a cosmopolitan age. New York: Routledge.

Franch, S. (2019) 'Global citizenship education between qualification, socialization, and subjectification'. In Peterson, A., Stahl, G. and Soong, H. (eds) The Palgrave Handbook of Citizenship and Education. Cham: Palgrave Macmillan.

Franch, S. (2020) 'Reconceptualising citizenship education towards the global, the political and the critical: Challenges and perspectives in a province in Northern Italy'. In Bamber, P. (ed.) Teacher Education for Sustainable Development and Global Citizenship: Critical perspectives on values, curriculum and assessment. New York: Routledge, 144-55.

Glaser, B.G. and Strauss, A.L. (1967) The Discovery of Grounded Theory: Strategies for qualitative research. New York: Aldine de Gruyter.

Jefferess, D. (2008) 'Global citizenship and the cultural politics of benevolence'. Critical Literacy: Theories and Practices, 2 (1), 27-36.

Jorgenson, S. and Shultz, L. (2012) 'Global citizenship education (GCE) in post-secondary institutions: What is protected and what is hidden under the umbrella of GCE?'. Journal of Global Citizenship and Equity Education, 2 (1), 1-22.

Mannion, G., Biesta, G., Priestley, M. and Ross, H. (2011) 'The global dimension in education and education for global citizenship: Genealogy and critique'. Globalisation, Societies and Education, 9 (3-4), 443-56. 
Marshall, H. (2011) 'Instrumentalism, ideals and imaginaries: Theorising the contested space of global citizenship education in schools'. Globalisation, Societies and Education, 9 (3-4), 411-26.

Mylius, B. (2013) 'Towards the unthinkable: Earth jurisprudence and an ecocentric episteme'. Australian Journal of Legal Philosophy, 38, 102-22.

OECD (Organisation for Economic Co-operation and Development) (2018) Preparing Our Youth for an Inclusive and Sustainable World: The OECD PISA global competence framework. Paris: OECD Publishing.

Oxley, L. and Morris, P. (2013) 'Global citizenship: A typology for distinguishing its multiple conceptions'. British Journal of Educational Studies, 61 (3), 301-25.

Pashby, K. (2016) 'The global, citizenship, and education as discursive fields: Towards disrupting the reproduction of colonial systems of power'. In Langran, I. and Birk, T. (eds) Globalization and Global Citizenship: Interdisciplinary approaches. London: Routledge, 69-86.

Provincia autonoma di Trento (2015). Verbale di deliberazione della giunta provinciale. Aggiornamento del quadro dell'offerta scolastica ed educativa provinciale e indirizzi alle istituzioni scolastiche e formative per la XV legislatura [Provincial guidelines for the schooling system]. Reg.delib. n. 1907, 02 November.

Provincia autonoma di Trento (2016). Verbale di deliberazione della giunta provinciale. Approvazione delle linee guida di indirizzo per le attività di cooperazione internazionale allo sviluppo [Provincial guidelines for international cooperation]. Reg.delib.n. 153, 12 Febbraio.

Rapoport, A. (2015) 'Global citizenship education: Classroom teachers' perspectives and approaches'. In Harshman, J., Augustine, T. and Merryfield, M. (eds) Research in Global Citizenship Education. Charlotte, NC: Information Age Publishing, 119-35.

Sant, E., Davies, I., Pashby, K. and Shultz, L. (2018) Global Citizenship Education: A critical introduction to key concepts and debates. London: Bloomsbury Academic.

Shultz, L., Abdi, A.A. and Richardson, G.H. (2011) 'Global citizenship education and the role of the academy: A critical introduction'. In Shultz, L., Abdi, A.A. and Richardson, G.H. (eds) Global Citizenship Education in Post-Secondary Institutions: Theories, practices, policies. New York: Peter Lang, 1-10.

Tarozzi, M. (2008) Che cos'è la Grounded Theory. Rome: Carocci.

Tarozzi, M. and Inguaggiato, C. (2018) 'Implementing global citizenship education in EU primary schools: The role of government ministries'. International Journal of Development Education and Global Learning, 10 (1), 21-38.

Thornberg, R. (2012) 'Informed grounded theory'. Scandinavian Journal of Educational Research, 56 (3), 243-59.

UNESCO (United Nations Educational, Scientific and Cultural Organization) (2015) Global Citizenship Education: Topics and learning objectives. Paris: United Nations Educational, Scientific and Cultural Organization. 